\title{
Malnutrition Among Basic Schools' Children of Elshagalwa Village, Shendi Locality, Sudan
}

\author{
Faroug Bakheit Mohamed Ahmed ${ }^{1}$, Esam-Eddin Bakheit Mohamed Ahmed ${ }^{2}$ \\ ${ }^{1}$ Department of Biochemistry, Faculty of Science and Technology, Shendi University, Shendi, Sudan \\ ${ }^{2}$ Department of ENT, Faculty of Medicine, Shendi University, Shendi, Sudan
}

Email address:

farougmhmd@gmail.com (F. B. M. Ahmed)

\section{To cite this article:}

Faroug Bakheit Mohamed Ahmed, Esam-Eddin Bakheit Mohamed Ahmed. Malnutrition Among Basic Schools' Children of Elshagalwa Village, Shendi Locality, Sudan. International Journal of Nutrition and Food Sciences. Vol. 5, No. 2, 2016, pp. 134-138. doi: 10.11648/j.ijnfs.20160502.17

Received: February 11, 2016; Accepted: March 5, 2016; Published: March 28, 2016

\begin{abstract}
In this cross-sectional community based study, first class children of six basic school children (three male schools and three female schools) of Elshagalwa village, north of Shendi town were subjected to determine their nutritional status by assessing total serum protein and serum albumin. The method s of our study included a questionnaire in order to determine the nutrition status of child; usually consumed foodstuff and socioeconomic status of child's family, and biochemical parameters such as total serum protein and serum albumin. The study showed that the mean $\pm \mathrm{SD}$ of total serum protein and serum albumin of study sample were $6.4 \pm 0.9 \mathrm{~g} / \mathrm{dl}$ and $4.0 \pm 0.6 \mathrm{~g} / \mathrm{dl}$ respectively. The present study also revealed that most of pupils had normal nutrition status $(87.2 \%)$ and $12.8 \%$ of children were suffering from malnutrition, $5.6 \%$ of them were with moderate malnutrition, $94.4 \%$ with mild malnutrition and there are no cases with severe malnutrition. The study suggested that the child sex (gender) showed no effect on children nutritional status, parents' education level particularly of mothers had a positive effect on nutritional status and family size had a negative effect on nutritional status.
\end{abstract}

Keywords: Khalwa, Kissra, Malnutrition, Mild, Moderate, Malnourished

\section{Introduction}

Nutrition may be defined as the sum of process by which a person obtain, ingests, absorbs and metabolize those substances essential for life under all environmental circumstances [1]. Good nutrition helps to prevent acute and chronic illnesses and to develop physical and mental potential [2]. Good nutrition is reflected in growth, providing height, weight, appropriate bodily function and freedom from illnesses associated with malnutrition in childhood [3]. Nutritional status of children is an indicator of a number of phenomena; they are access to food, availability of medical services and their use, care given to the children, and allocation of food within the household members [4].

To growth strong and healthy children need a lot of healthy food, care and attention. When the child is not growing properly or is sick, his weight will not increase and may even decrease [5]. Varieties of nutrients are important for body function and include the following:
- Nutrients for building (protein, minerals, vitamins and water).

- Nutrients for energy (carbohydrates, fat and proteins).

- Nutrients for regulation of body process (minerals, vitamins and water) [6].

Energy: energy needs of children vary at different ages and under various conditions. The approximate average expenditures of energy in children of $6-12$ years are; basal metabolism $50 \%$, growth $12 \%$, physical activity $25 \%$ and fecal loss mainly as unabsorbed fat about $8 \%$.

Carbohydrates: supply most of the body energy needs. The effect of deficiency is ketosis, whereas the effect of excess is overweight. The sources of carbohydrates are milk, cereals and fruits.

Proteins: it constituents $20 \%$ of adult body weight. Children in the age of $6-10$ years and have weight of $20-28$ kgs need $24 \mathrm{~g}$ of protein daily.

Fats: fats are efficient stores of energy. They provide palatability to food and serve as vehicles for fat soluble vitamins. 
Water: human needs water are related to caloric consumption, to insensible loss and to specific gravity in the urine. The six years old child of $20 \mathrm{~kg}$ weight needs $1800-$ $2000 \mathrm{ml}$ of water daily.

Vitamins: Vitamins are organic substances which the body require in small amount of its metabolism, yet can't make for itself at least in sufficient quantity. Diseases result from deficiencies of vitamins; eg: rickets a disease of children in which the bones are softened and deformed. It arises from the deficiency of vitamin D and failure to absorb calcium from the intestine and resorption from bones.

Minerals: man's foods wether of vegetable or animal origin is composed of complex minerals salts which contain several elements. Calcium, phosphorus, magnesium, and sulphur are important components of bones and other supporting tissues [7].

Lack of access to highly nutritious foods, especially in the present context of rising food prices, is a common cause of malnutrition [8]. Malnutrition is the condition that develops when the body does not get the right amount of the vitamins, minerals, and other nutrients it needs to maintain healthy tissues and organ function [9]. Malnutrition occurs in people who are either undernourished or over nourished. Undernutrition is a consequence of consuming too few essential nutrients or using or excreting them more rapidly than they can be replaced. Malnutrition among children have lifelong implications, its outcomes not only cover the whole life but are transferred from one generation to another. Malnutrition is not the same thing as hunger, although they often go together. People who are chronically malnourished lack the nutrients needed for proper health and development. Someone can be malnourished for a long or short period of time, and the condition may be mild or severe. People who are malnourished are more likely to get sick and, in severe cases, might even die [10].

Over 10 million children aged less than five years (underfive children) die annually from preventable and treatable illnesses almost all these deaths occur in poor countries [11]. Currently, 195 million under-five children are affected by malnutrition; $90 \%$ of them live in sub- Saharan Africa and South Asia [12]. Malnutrition in sub-Saharan Africa contributes to high rates of childhood morbidity and mortality. However, little information on the nutritional status of children is available from informal settlements [13]. There are main symptoms of malnutrition which include; hair is thin, tightly curled, and pulls out easily. Joints ache and bones are soft and tender. The gums bleed easily. The tongue may be swollen or shriveled and cracked. Visual disturbances include night blindness and increased sensitivity to light and glare. Other symptoms of malnutrition are Anemia, diarrhea, disorientation, night blindness, irritability, anxiety, and attention deficits [14].

Malnutrition is the most recognizable and perhaps most untoward consequence of poverty in children [15]. News reports from health facilities suggested that moderately malnourished children were becoming severely malnourished due to acute food shortages[16]. Undernutrition and micronutrient deficiencies contribute substantially to the global burden of disease. Impoverished communities experience high rates of undernutrition and increased exposure to infectious diseases caused by crowding and inadequate sanitation [17].

A malnourished person finds that their body has difficulty doing normal things such as growing and resisting disease. Physical work becomes problematic and even learning abilities can be diminished. Disease and malnutrition are closely linked. Sometimes disease is the result of malnutrition, sometimes it is a contributing cause. In fact, malnutrition is the largest single contributor to disease in the world, according to the UN's Standing Committee on Nutrition (SCN) [18]. Malnutrition at an early age leads to reduced physical and mental development during childhood. Stunting, for example, affects more than 147 million preschools in developing countries, according to SCN's World Nutrition Situation 5th report.

Evidence is accumulating that early malnutrition increases the risk of numerous chronic diseases later [19]. Associations of early undernutrition with diabetes, hypertension, renal disease, and cardiovascular disease mean that child undernutrition also leads to high adult health care costs [20]. By treating childhood malnutrition in the first 1,000 days of a child's life, UNICEF has helped cut the number of children badly affected by stunting by nearly 100 million since 1990 [21].

\section{Justifications of the Study}

- Lack of information on nutrition of children specialized in Shendi locality in general and Elshagalwa area in particular.

- Focus attention on the importance of the nutritional supplementation to reach high standard of somatic and consequently psychiatric and mental health for children.

\section{Objective of the Study}

The present study aims to evaluate nutritional status of first class ( $6-7$ years) of basic schools of Elshagalwa village in Shendi locality, Sudan.

\section{Materials and Methods of the Study}

\subsection{Study Sample}

First class children (6 - 7 years) of six basic school children (three male and three female) of Elshagalwa village, north of Shendi town were subjected to determine their nutrition status by assessing total serum protein and serum albumin.

\subsection{Reagents}

- Copper ion $6 \mathrm{mmol} / \mathrm{l}$.

- Bromo cresol green.

- Protein standard $(7 \mathrm{~g} / \mathrm{dl})$.

- Albumin standard (5g/dl). 


\subsection{Equipments and Apparatus}

- Centrifuge.

- Digital colorimeter.

- Test tubes.

- Micropipette.

\subsection{Procedure}

After informed consent and use of alcohol anti septic (70\% ethanol) $3 \mathrm{ml}$ of venous blood was collected from using disposable syringe. The blood was collected in lithium heparin container and separated by centrifuge for 3 minutes, $3000 / \mathrm{rpm}$. Serum total protein was estimated by Biuret method in which protein of the sample reacts with copper ion in alkaline medium forming a colored complex that could be measured by colorimeter at $545 \mathrm{~nm}$ filter.

Serum albumin was estimate by using dye binding bromo cresol green method of Domus modified by Spencer and price (1977). In this method sample albumin reacts with bromo cresol green in acid medium forming a colored complex which was measured calorimetrically at $630 \mathrm{~nm}$ filter.

\subsection{Calculations}

- Serum protein $g / d l$

$=$ absorbance of sample $\quad x 7$ (standard concentration) Absorbance of standard

Serum albumin $\mathrm{g} / \mathrm{dl}$

$=$ absorbance of sample $\times 5$ (standard concentration) Absorbance of standard

\subsection{Statistic Analysis}

The data was analyzed by using statistical package for social science (SPSS), windows version16, 2012 SPSS, Inc, Chicago, IL, and USA. Percentage in addition mean and standard deviation, and $\mathrm{p}$ value were calculated.

\section{Results}

The study showed that the mean \pm standard deviation (SD) of total serum protein and serum albumin of study sample were in the normal range, Table 1.

Table 1. Biochemical parameters of study sample.

\begin{tabular}{lll}
\hline Parameters & Mean & SD \\
\hline Serum total protein $(\mathrm{g} / \mathrm{dl})$ & 6.4 & 0.9 \\
Serum albumin $(\mathrm{g} / \mathrm{dl})$ & 4.0 & 0.0 \\
\hline
\end{tabular}

Table 2. Nutritional status of children.

\begin{tabular}{|c|c|c|c|c|}
\hline \multirow[t]{2}{*}{ Nutrition status } & \multirow[t]{2}{*}{ Normal } & \multicolumn{3}{|c|}{ Malnourished } \\
\hline & & & Severe & - \\
\hline \multirow[t]{2}{*}{ Parentages $(\%)$} & 87.2 & 12.8 & Moderate & 5.6 \\
\hline & & & Mild & 94.4 \\
\hline
\end{tabular}

Most of pupils (87.2\%) had normal nutrition status and $12.8 \%$ of children were suffering from malnutrition. $5.6 \%$ of malnourished children were with moderate malnutrition, $94.4 \%$ with mild malnutrition and there are no cases with severe nutrition, Table 2.

Foodstuffs had variable correlation relations with biochemical parameters. Liver, eggs and fish consumption had shown correlation relation with total serum protein and serum albumin at $\mathrm{p}<0.01$. The foodstuffs consumed by children of study sample were showed in table 3 .

Table 3. Foodstuff consumed by child.

\begin{tabular}{llll}
\hline \multirow{2}{*}{ Items } & Frequency & & \\
\cline { 2 - 4 } & Daily & Weekly & Monthly \\
\hline Bread & Daily & weekly & Monthly \\
Kissra & 96.8 & 3.2 & 0.0 \\
Rice & 87.1 & 12.1 & 0.8 \\
Legume & 1.6 & 58.9 & 39.5 \\
Milk & 91.9 & 8.1 & 0.0 \\
Meat & 91.9 & 8.1 & 0.0 \\
Liver & 20.4 & 22.6 & 57.0 \\
Fish & 0.2 & 10.4 & 74.9 \\
Eggs & 0.8 & 9.7 & 62.1 \\
Vegetable & 1.5 & 19.5 & 79 \\
Fruit & 48.7 & 51.3 & 0.0 \\
Dates & 5.6 & 63.7 & 30.6 \\
Sweets & 25 & 67.7 & 7.3 \\
\hline
\end{tabular}

Children sex had no effect on the nutritional status of the study sample children at this period of age (6-7 years age), Table 4.

Table 4. Distribution of malnourished children according to child gender.

\begin{tabular}{lll}
\hline \multirow{2}{*}{ Child sex } & \multicolumn{2}{l}{ Malnourished children } \\
\cline { 2 - 3 } & Moderate \% & Mild \% \\
\hline Male & 2.7 & 47.3 \\
Female & 2.9 & 47.1 \\
Total \% & 5.6 & 94.4 \\
\hline
\end{tabular}

Serum total protein and serum albumin revealed correlative relation with mother education and occupation, and family size and income, all at the same $\mathrm{p}$ value $(\mathrm{p}<$ $0.05)$, Tables $5,6,7,8,9$ respectively.

Table 5. Malnourished children according to parent's education level.

\begin{tabular}{|c|c|c|c|}
\hline \multirow{2}{*}{ Education level } & \multirow{2}{*}{ Parents } & \multicolumn{2}{|c|}{ Malnourished children } \\
\hline & & Moderate \% & Mild \% \\
\hline \multirow{2}{*}{ Illiterate } & Father & 1.6 & 9.7 \\
\hline & Mother & 2.4 & 15.3 \\
\hline \multirow{2}{*}{ Khalwa } & Father & 1.6 & 12.1 \\
\hline & Mother & 0.8 & 1.6 \\
\hline \multirow{2}{*}{ Primary } & Father & 0.8 & 20.2 \\
\hline & Mother & 1.6 & 33.1 \\
\hline \multirow{2}{*}{ Secondary } & Father & 0.8 & 27.4 \\
\hline & Mother & 0.0 & 12.1 \\
\hline \multirow{2}{*}{ University } & Father & 0.0 & 4.8 \\
\hline & Mother & 0.0 & 4.8 \\
\hline
\end{tabular}


Table 6. Malnourished children according to mother's occupation.

\begin{tabular}{lll}
\hline \multirow{2}{*}{ Mother occupation } & \multicolumn{2}{l}{ Malnourished children } \\
\cline { 2 - 3 } & Moderate \% & Mild \% \\
\hline House wife & 5.6 & 88.7 \\
Laborer & 0.0 & 0.9 \\
Government employee & 0.0 & 4.8 \\
Total \% & 5.6 & 94.4 \\
\hline
\end{tabular}

Table 7. Malnourished children according to family size.

\begin{tabular}{lll}
\hline \multirow{2}{*}{ Family size } & \multicolumn{2}{l}{ Malnourished children } \\
\cline { 2 - 3 } & Moderate \% & Mild \% \\
\hline$\leq 5$ members & 0.0 & 5.6 \\
$6-9$ members & 2.4 & 38.7 \\
$\geq 10$ members & 3.2 & 50.1 \\
Total \% & 5.6 & 94.4 \\
\hline
\end{tabular}

Table 8. Malnourished children according to socio economic status.

\begin{tabular}{lll}
\hline \multirow{2}{*}{ Socio economic status } & \multicolumn{2}{l}{ Malnourished children } \\
\cline { 2 - 3 } & Moderate \% & Mild \% \\
\hline Very low & 4.1 & 40.3 \\
Low & 1.5 & 37.2 \\
Middle & 0.0 & 13.7 \\
High & 0.0 & 3.2 \\
Total \% & 5.6 & 94.4 \\
\hline
\end{tabular}

Parents' separation revealed no effect on the nutritional status of children, Table 9.

Table 9. Malnourished children according to parent's separation.

\begin{tabular}{lll}
\hline \multirow{2}{*}{ Parents separation } & \multicolumn{2}{l}{ Malnourished children } \\
\cline { 2 - 3 } & Moderate \% & Mild \% \\
\hline Yes & 2.5 & 42.6 \\
No & 3.1 & 51.8 \\
Total \% & 5.6 & 94.4 \\
\hline
\end{tabular}

\section{Discussion}

Normalizing nutritional status starts with a nutritional assessment. This process enables a clinical nutritionist or registered dietician to confirm the presence of malnutrition, assess the effects of the disorder, and formulate diets that will restore adequate nutrition. Poor nourishment results from improper diet or from some defect in metabolism that prevents the body from using its food properly [3].

Parents' education level had an effect on the nutritional status of their children. Mother education level was generated positive influences on nutritional status of their children and this might be explained as an increasing in awareness of importance of proper feeding for growing children, child care and knowledge of how these factors help to improve the child health and nutritional status. Whereas father education level was exerted less implication than that of the mother on nutritional status of their children, and this might be explained as that fathers spend most of their daytime and exertion at work, thus no spared time to be specified for looking after children.

The nutritional status of children was greatly influenced by parents' occupation. Father occupation revealed association with children nutritional status and as it represents the determinant of family income. Father income is directly proportional with quantity and quality food provides to the family, therefore, it produced very obvious implication on the nutritional status of their children. The effect of mother occupation on the nutritional status of children was found to be marked, the possible explanation of which was that the working mothers improve their children nutritional status through the additional income to the family by the wages they gain.

There was significant association between the nutritional status of children and family size and this could be attributed to an increase in food consumption in relation to low family income which was found to be depending on father occupation.

The social state of parents (separation) did not affect the nutritional status of their children. This could be attributed to that in children whose parents separated there was relationship between parents, therefore, whether with father or mother the child lived, would be in living level not widely variable in addition to the care and psychological support from uncles, aunts, grandmothers and grandfathers because of extended families.

The children in the sample subjected to the study were from Elshagalwa village in River Nile state, where most daily consumed food constituents were Kissra, bread, legumes, milk, meat and vegetables. This could be said to contribute to observation of clinical signs of malnutrition in small percentage of studied sample. The daily consumed stuffs could be regarded enough for the majority of children to much most of the daily requirements of nutrients responsible for the clinical signs such as Riboflavin (B2), Niacin (B3), and proteins. However, the weekly and monthly intake benefits were considerable in participation and correction of the lack of clinical sign-related nutrients.

The village where the study was conducted is selfsufficient of vegetables, many sorts of legumes and milk. Surplus milk is marketed to near town (Shendi). A considerable number of populations work in fishing. Although this occupation didn't appear among the occupations of fathers of the study sample children, the village represented one of the most important areas supplying Shendi town with fishes and many types of legumes.

The site of the village near Shendi town put it on communication with Shendi University in the field maternal and child care, reproductive health and nutrition programs and this lead to spread of health education.

\section{Conclusion and Recommendation}

The mean value of total serum protein and serum albumin of first class children of Elshagalwa village was in the normal range. Poverty and lack of food are the primary reasons of malnutrition. To improve the nutritional status of children health and nutrition education could be further extended, and an increase of family income to improve the economic status. 


\section{References}

[1] Dodge P. R., Prensky A. L. and Feign R. D. (1975). Nutrition and the developing nervous system. C. V. Mosby Company. pp 180-82.

[2] Nelson W. E., Richard E. B and Robert M. K. (1996). Textbook of pediatrics. W. B. Sanders company - London, 15thedition, $\mathrm{p} 144$.

[3] Estwood M. (1997). Principles of human nutrition, Chapman and Hall, London, 1st edition, p 508.

[4] RanaEjaz Ali Khan and Muhammad Ali Raza. (2014). Nutrition status of children in Bangladesh: measuring composite index of anthropometric failure (CIAF) and its determinants. Pakistan Journal of Commerce and Social Sciences, 2014, Vol. 8 (1), 11-23.

[5] World Health Organization (1995). The state of child in the Eastern Mediterranean region. EMR, business man publication, series 4, 2nd ed. Revised, p 47-167.

[6] Bennion M. (1985). Introductory food. 8th ed. Macmillan publishing company, New York: p 63.

[7] Passmore R. and Eastwood M. A. (1986). Davidson and Passmore Human Nutrition and Dietetic. 8thed. Churchill living stone, Edinburge, pp 90, 117, 422.

[8] World Health Organization (2016). Malnutrition, maternal, newborn, child and adolescent. www.who.int/maternal-childadolescent.

[9] Beers, Mark H., MD, and Robert Berkow, MD, editors. "Malnutrition." Section 1, Chapter 2. In The Merck Manual of Diagnosis and Therapy. Whitehouse Station, NJ: Merck Research Laboratories, 2004.

[10] Hunger and malnutrition. www.Kidshealth.org/parent/growth/feeding/hunger.html
[11] Black RE, Morris SS, Bryce J. Where and why are10 million children dying every year? Lancet 2003; 361: 2226-34.

[12] Black RE, Allen LH, Bhutta ZA, Caulfield LE, de OnisM, Ezzati $\mathrm{M}$ et al.; Maternal and Child UndernutritionStudy Group. Maternal and child undernutrition: global and regional exposures and health consequences. Lancet 2008; 371: 243-60.

[13] Dooling K., Feikin D., Talley L, and Robert F. Breiman R. (2011). Nutritional status of under-five children living in an informal urban settlement in Nairobi, Kenya. J Health PopulNutr 2011 Aug; 29(4): 357-363.

[14] Flancbaum, Louis, MD, with Erica Manfred and Deborah Biskin. The Doctor's Guide to Weight Loss Surgery. West Hurley, NY: Fredonia Communications, 2001.

[15] Goel MK, Mishra R, Gaur DR, Das A. Nutrition surveillance in 1-6 years old children in urban slums of a city in northern India. Internet J Epidemiol2007; 5: 1.

[16] United Nations Children's Fund. Kenya civil unrest: UNICEF responds to the immediate needs for children and women affected by post-election violence. Nairobi: United Nations Children's Fund, 2008: 3.

[17] Ezzati M., Lopez A. D., Rodgers A., Hoorn S. Vander, Murray C. J. Comparative Risk Assessment Collaborating Group. Selected Major Risk Factors and Global and Regional Burden of Disease. Lancet. 2002; 360(9343): 1342-43.

[18] World Food Programme. (2016). https://www.wfp.org/hunger/malnutrition

[19] Caballero B. Early Nutrition and Risk of Disease in the Adult. Public Health Nutrition. 2001; 4(6A): 1335-36.

[20] Gluckman P. D., Hanson M. A. Living with the Past: Evolution, Development, and Patterns of Disease. Science. 2004; 305(5691): 1733-36.

[21] UNICEF (2015). Child survival. Nutritional and food security. UNICEF works to give kids a healthy start. www.unicefusa.org/mission/survival/nutrition 